\title{
EFEITOS DA IMIGRAÇÃO ITALIANA NA CONSTITUIÇÃO DA IDENTIDADE NA MOOCA
}

\author{
Márcia de Oliveira Lupia \\ Mestre em Linguística pela Universidade Cruzeiro do Sul (UNICSUL) \\ marcialupia@hotmail.com
}

\section{RESUMO}

Este artigo tem por objetivo estudar os efeitos da imigração italiana na memória e na constituição identitária do sujeito italiano e do descendente de italianos do bairro da Mooca (SP), por meio da análise de recortes discursivos extraídos de entrevistas feitas com residentes do local. A escolha desse grupo deve-se ao fato de que, mesmo após cem anos do grande fluxo migratório do início do século XX na capital paulista, ainda hoje vemos fortes marcas do italiano na língua e nos costumes do bairro. A fim de alcançarmos nossos objetivos, utilizamos nas análises os estudos da Análise de Discurso de linha francesa de Pêcheux (1995) e estudos relacionados à constituição do sujeito no entre-línguas de Coracini $(2003,2013)$. Depreendemos das análises que tanto o brasileiro, descendente, quanto o italiano podem ser considerados ítalo-brasileiros que (re)inventaram e (re)significaram língua e costumes na tentativa de preservação de suas raízes.

Palavras-chave: memória, identidade, discurso, Mooca, italianos.

\section{ABSTRACT}

The purpose of this paper is to study the effects of Italian immigration in the memory and in the identity constitution of the Italian and the Italian descendant subject from Mooca (São Paulo), analyzing the discursive sequences extracted from interviews with local residents. We chose this group because even after one hundred years of the great migratory flow of the early twentieth century in São Paulo, we still can see strong marks of Italian in both language and culture of the neighborhood. In order to reach our objectives, we have used the studies of the French Speech Analysis of Pêcheux (1995) and studies related to the constitution of the subject in the "between-languages" of Coracini (2003, 2013). We educe from the analysis that Brazilians, the descendants, and the Italians can be considered ItalianBrazilian subjects whom (re) invented and (re) meant language and culture in an attempt to preserve their roots.

Keywords: memory, identity, discourse, Mooca, Italian people. 


\section{Considerações iniciais}

Entre apressados passos diluídos nas ruas e avenidas compostas por incontáveis arranha-céus encontram-se pessoas cujos rostos revelam uma miscelânea de traços dos povos que ajudaram a construir a cidade de São Paulo. Essa herança não se observa apenas nos traços físicos de cada um de seus habitantes, mas na memória e identidade da cidade por meio de lugares, costumes e língua.

Um traço forte e que nos chamou a atenção para este estudo foi deixado pelos imigrantes italianos que passaram a fazer parte da população paulistana no início do século XX. Esse período foi marcado pelo grande fluxo migratório de europeus que saíram de suas pátrias em busca de melhores condições de vida. Na Itália, a maior parte da população sofria com a pobreza socioeconômica advinda de seu processo de unificação. Eram tantos imigrantes italianos em São Paulo que Cenni (2003) relata a surpresa de um mineiro que, ao visitar a capital paulista em 1902, deparou-se com as pessoas falando em italiano por todos os cantos da cidade. As marcas deixadas pelos imigrantes italianos ainda resistem em São Paulo e já serviram até de inspiração ao autor da telenovela "A próxima vítima", que foi ao ar pela rede Globo em 1995, e teve como um dos principais cenários o bairro da Mooca, considerado um dos maiores redutos de italianos na capital.

A Mooca, bairro periférico da zona leste de São Paulo, por ser estrategicamente situada para vinda de matéria-prima e escoamento de produtos, entre o rio Tamanduateí e a ferrovia Santos-Jundiaí, abrigou um dos maiores polos industriais brasileiros e foi a região da capital que mais recebeu imigrantes italianos para os trabalhos em suas indústrias. Por conseguinte, os costumes e a língua da Itália marcaram a memória e a identidade de seus habitantes e descendentes. Exemplo disso é o pedido de tombamento ${ }^{i}$ 
feito ao Conselho Municipal de Preservação do Patrimônio Histórico e Ambiental da Cidade de São Paulo (Conpresp) referente ao "mooquês", denominação criada pelos italianos e descendentes do bairro para falar do sotaque local, como patrimônio imaterial do município de São Paulo.

Como e por que, mesmo após mais de cem anos passados do grande contingente migratório no bairro, as cicatrizes italianas ainda marcam a memória e a identidade na Mooca? O objetivo deste artigo é depreender do discurso do italiano e descendente de italianos residentes na Mooca como a língua e os costumes trazidos da Itália vêm constituindo a identidade do bairro. Para tanto, utilizaremos a base teórica da Análise de Discurso de linha francesa de Pêcheux (1995), Orlandi (2009) e Authier-Revuz (1990,1998), os estudos sobre identidade e memória de Hall (2000) e Candau (2014) e os estudos sobre a constituição do sujeito no entre-línguas de Coracini $(2003,2013)$.

O corpus de análiseii é constituído por recortes discursivos provenientes de entrevistas feitas com italianos e descendentes de italianos residentes no bairro da Mooca e nascidos entre os anos de 1930 e 1940. Aqueles nascidos nessa década vivenciaram o último suspiro do grande fluxo migratório no bairro.

Estudos dos efeitos da imigração no Brasil justificam-se pela importante contribuição à Linguística e às Ciências Humanas e Sociais no que tange à problematização de políticas no ensino de línguas em contexto de imigração e na inclusão social desses grupos nesse cenário. Pesquisas como as de Payer (1999), Eckert-Hoff (2010, 2016) e Lupia (2017) serviram como norte para a estruturação deste trabalho.

Além destas considerações iniciais, o artigo conta com uma explanação teórica, seguidamente da análise dividida em "Língua na língua" e "Língua Materna?” e, por último, algumas considerações finais acerca de nossos achados. 


\section{Bases teóricas}

Nosso ponto de partida é a Mooca e seu grupo de residentes. Para fins deste estudo, faz-se necessário trazermos como vislumbramos o bairro. Coadunando-nos a Candau (2014, p. 157), temos a Mooca como um lugar de memória: “existem 'regiõesmemória' (Vendeia, Alsacia, Cevenol) ou cidades-memória (Jerusalém, Roma, etc.), e mesmo bairros onde se afirmam com força as identidades regionais ou locais". Em complemento ao autor, trazemos as observações de Bosi (2003) acerca da relação entre bairro, memória e identidade. Ela considera o bairro como um lugar comum a um grupo e que pouco a pouco traz sentido de identidade, já que dentro dele existe um sentimento de pertencimento a uma tradição, uma maneira de ser.

Sobre os sujeitos desta pesquisa, entendemos, da mesma forma que Hall (2000), que são sujeitos pós-modernos, detentores de identidades não-fixas. A identidade da qual falamos é aquela que o autor traz em seus estudos: fragmentada, fraturada; são identidades "construídas ao longo de discursos, práticas e posições que podem se cruzar e ser antagônicas" (HALL, 2000, p. 108). É um processo contínuo, inacabado e marcado pela alteridade e estranheza. Esse sujeito da alteridade constitui-se na e pela linguagem e traz as marcas dos outros que o constituem em seu discurso. É por meio da heterogeneidade nesse discurso que passaremos a entender a constituição desse sujeito imigrante, o sujeito do entre-línguas ${ }^{\mathrm{iii}}$ e culturas portuguesa, italiana, brasiliana, ítalobrasileira.

Para fins deste estudo, trazemos algumas de nossas percepções sobre o que entendemos sobre língua e estar entre-línguas. Assim como Payer (2007), entendemos a 
língua materna e a língua nacional como dimensões diferentes da linguagem na ordem da memória. Podemos dizer que elas não são necessariamente a mesma e consideramos que o funcionamento discursivo das línguas materna e nacional está vinculado à história e à ideologia, juntamente ao modo como são interpretadas e por quem.

De forma a complementar, Coracini (2013) traz considerações acerca de línguas estrangeiras e maternas, das quais nos valemos para as análises. A autora entende que

\begin{abstract}
toda língua é estrangeira, na medida em que provoca em nós estranhamentos, e toda língua é materna, na medida em que nela nos inscrevemos, em que ela se faz ninho, lar, lugar de repouso e de aconchego; ou melhor, toda língua é materna e estrangeira ao mesmo tempo. Por isso, não é possível, em língua, sentir-se em casa: somos sempre exilados em nossa própria morada, exílio que herdamos ou que nos é imposto pela classe social, pelo grupo étnico, pela cultura, enfim, pelo lugar em que me escrevo e inscrevo (CORACINI, 2013, p. 48).
\end{abstract}

Coadunando-nos à Celada e Payer (2016), entendemos que um sujeito se encontra entre-línguas quando está exposto em processos que o envolvam com as línguas das quais ele é constituído, sejam elas maternas ou estrangeiras.

Para as análises, acreditamos que o dispositivo da Análise de Discurso de linha francesa é o que mais se adequa ao nosso estudo. Nessa abordagem, temos, segundo Pêcheux (1995), o discurso como efeito de sentidos entre um sujeito A e outro B. Em outras palavras, a produção de sentidos não tem ligação apenas com a transmissão de informações, já que

no funcionamento da linguagem, que põe em relação sujeitos e sentidos afetados pela língua e pela história, temos um complexo processo de constituição desses sujeitos e produção de sentidos e não meramente transmissão de informação. São processos de identificação do sujeito, 
de argumentação, de subjetivação, de construção da realidade etc. (ORLANDI, 2009, p. 21).

Nessa perspectiva, a memória está ligada ao esquecimento: não é o esquecimento causado por alguma enfermidade; o esquecimento de que versa a Análise do Discurso é aquele do inconsciente, estruturante e faz parte da constituição do sujeito (PÊCHEUX, 1995). Esses esquecimentos, segundo Lupia (2017):

silenciam sentidos outros. Para que as palavras proferidas pelo sujeito façam sentido é necessário que haja um apagamento dos outros dizeres, de modo que eles se instalem na memória discursiva e quando acionados pelos sujeitos, estes sintam que aquelas palavras os pertençam, sendo que na realidade já foram ditas por outras pessoas (LUPIA, 2017, p. 48).

Faz-se oportuno trazer à baila as percepções sobre a heterogeneidade discursiva estudada por Authier-Revuz (1990). A relação entre língua e exterior é refletida na materialidade linguística, levando-nos a outras vozes e discursos que constituem o sujeito: “nenhuma palavra é 'neutra', mas inevitavelmente 'carregada', 'ocupada', 'habitada', 'atravessada' pelos discursos nos quais 'viveu sua existência socialmente sustentada'"' (AUTHIER-REVUZ, 1990, p. 27).

Esse encontro entre sujeito e língua é o que confere (re)significação às identidades. Voltando-se ao sujeito imigrante, Coracini (2013) traz ensinamentos dos quais nos apropriaremos nas análises. A autora acredita que todo o ato de enunciação transforma esse sujeito e acaba transformando a língua. A submissão à língua da colônia de um povo colonizado ou de imigrantes a quem são impostas línguas estrangeiras é um processo que deixa cicatrizes, marcando suas identidades. Nesse processo, inconsciente, o imigrante ou colonizado também impõe sua cultura, costumes e línguas aos 
colonizadores. Daí, temos os sujeitos constituídos no entre-línguas. A autora ainda traz uma questão que nos interessa mediante um estudo como este: como esse sujeito que se encontra entre-línguas, constituído de várias línguas e culturas, mas aparentando ter apenas uma nessa constituição, habita uma língua que não o faz sentir-se em casa, dizer tudo o que deseja? A resposta está no fato de que não existe uma língua (inglesa, francesa, italiana), mas sim, línguas (inglesas, francesas, italianas). As línguas atravessam os sujeitos, constituindo-os, mas levam consigo as marcas desses sujeitos que já foram interpelados por outras línguas e culturas.

Após a exposição teórica, passaremos às análises dos recortes discursivos, os quais estão divididos em dois subtítulos: “Língua na língua” e “Língua Materna?”.

\section{Língua na língua}

As entrevistas feitas com os italianos e descendentes residentes no bairro da Mooca trazem nos recortes discursivos utilizados em nossas análises "fragmentos de discursos que carregam consigo fragmentos de uma realidade sócio-histórica" (CORACINI, 2003, p. 3). A influência dos italianos nos costumes e na língua pode ser observada ao longo das entrevistas acontecendo simultaneamente àquilo que esses imigrantes absorveram dos brasileiros: não sabemos onde começa a língua italiana e onde termina a língua portuguesa; não sabemos o quanto de italiano existe na culinária do bairro e qual a pitada de brasileiro que seus pratos levam.

A partir dessa constatação e instigados pelo fato de que o "mooquês" pode tornarse patrimônio histórico da cidade de São Paulo, voltamo-nos às incidências 
linguístico-discursivas observadas no discurso dos sujeitos desta pesquisa. Encontramos a língua acontecendo na língua, inconscientemente. Segundo Melman (1992),

do ponto de vista linguístico, nada se opõe à penetração de uma língua por outra língua e a tendência mecânica, espontânea, deveria ser o apagamento, da assimilação das línguas minoritárias. Por outro lado, o inconsciente não cria nenhum obstáculo à mixagem das línguas. Pode reter em seu seio palavras, locuções, fragmentos inteiros de discursos tomados de uma língua da infância que em seguida tornou-se estrangeira. $O$ inconsciente não é nem nacionalista, nem xenófobo (MELMAN, 1992, p. 16).

Dessa mixagem das línguas, abalizados nos estudos de Payer (1999), e observando as incidências linguísticas construídas pelo cruzamento de discursividades apagadas e ditas, pudemos depreender traços sonoros, morfossintáticos e lexicais que constituem tanto o sujeito italiano da Mooca quanto o descendente de italiano deste bairro: "a língua outra produz efeitos na relação constitutiva com o simbólico, afetando inevitavelmente aspectos de uma identidade" (ECKERT-HOFF, 2016, p. 215). Esses traços não somente estruturam o "mooquês", mas também nos permitem entender um pouco sobre a identidade e memória dos sujeitos de um bairro onde se viveu/vive uma Itália reinventada por eles; são marcas na língua as quais consideramos cicatrizes da constituição desse sujeito do entre-línguas.

Passaremos, a seguir, à exposição dos achados e aos comentários acerca deles. Inicialmente, chamou-nos a atenção a pronúncia dos entrevistados. Dentre as marcas fonéticas encontradas, quatro se destacam pela quantidade de vezes que ocorrem durante as entrevistas. Na primeira delas, observou-se que na fala desses sujeitos a nasalização é projetada mais perto da glote (vogal "posterior") de forma diferente do que nas demais variantes da língua portuguesa, em que ela ocorre mais próxima dos lábios 
(vogal "anterior"). Sendo assim, a vogal nasal posterior (média aberta) aparece no lugar da nasal central seguida de vogal posterior alta arredondada e palavras como confusão, então, irmão, região e pensão são pronunciadas pelos sujeitos desta pesquisa "confuson", “enton", irmon", "region", penson".

A segunda refere-se à " $r$ " vibrante múltipla. Na língua italiana não existe a pronúncia da letra " $r$ " com som gutural. Sendo assim, todos os sons de " $r$ " dos italianos e seus descendentes obedecem à pronúncia da língua de Dante, que Vieira (2010) traz em seus estudos como sendo o " $r$ " da expressão tipicamente paulistana "Orra, meu!". Detectamos tais incidências no enunciado dos sujeitos nas palavras como: Rosa, terra, "arrumô", terninho, terreno, enorme, conterrâneo, "retorná".

A terceira marca está relacionada à pronúncia da letra / t / plosiva alveolar. Segundo Payer (1999, p. 92), o "/ t / de 'tatu', ou o / t / conhecido como 'tipicamente paulistano"”. Pudemos identificá-lo em palavras como: "marmitinha", "bunitinho", terninho; arțista, esquentadinho, alistei.

A última marca fonética a ser exposta

refere-se ao / I / lateral alveolar em final de sílaba, como na palavra pólvora. No português falado e difundido no país, por exemplo, esse fonema apresenta som de / $\mathrm{m} /$; tomemos como exemplo o substantivo cálculo. Os brasileiros pronunciam o "I" do final da primeira sílaba "cau-" enquanto um italiano/descendente pronuncia utilizando "cal-" (LUPIA, 2017, p. 77).

As incidências dessa marca fonética puderam ser detectadas em: calçą, algụmas, difícil, Sul, infantil, algum.

Os sujeitos desta pesquisa, tanto italianos quanto descentes, fazem parte de um grupo de pessoas que tiveram de dedicar-se ao labor nas indústrias desde crianças, tendo 
por consequência pouca vivência escolar. Dessa forma, a língua que se aprendia era a italiana falada no lar e a língua portuguesa falada no trabalho nas indústrias. Os fonemas dessas línguas fundiram-se e passaram a fazer parte da memória linguístico-discursiva dos imigrantes, cujo discurso, inconscientemente, passou a ecoar nos enunciados de seus descendentes: "o sujeito não é a fonte do sentido; o sentido se forma na história através do trabalho da memória, a incessante retomada do já-dito; o sentido (...) escapa sempre" (MALDIDIER, 2003, p. 96).

Com o foco no já-dito que se perpetua na língua, passaremos a expor as marcas morfossintáticas das quais pudemos depreender as línguas portuguesa e italiana acontecendo concomitantemente nos dizeres dos sujeitos desta pesquisa. Cabe-nos ressaltar que o elencado a seguir é uma das possíveis análises acerca dessas ocorrências. Notamos, ao decorrer de todas as entrevistas e de maneira constante, a ausência da pronúncia do morfema "-s" marcador de plural nos substantivos e a ausência da desinência número-pessoal "-s" nos verbos, em grande parte, na 1a pessoa do plural: "ele fez os papel aqui", " fomo morar na Cônego Antônio Lessa”, "ela tinha muitos livro”, "nós já viemo", "poucas vez assim", "visitar os patrício", "todo os domingo", "16 ano começamo a fazer rádios", "nós chegamo em fevereiro", "passamo muita dificuldade", "mas uma das paixão que eu tinha". Sabe-se que a presença do "s" nesses casos está prevista na estrutura da Língua Portuguesa aos seus falantes. Ocorre que "o fato de que exista assim o outro interno em toda memória é [...] a marca do real histórico como remissão necessária ao outro exterior, quer dizer, ao real histórico como causa do fato de que nenhuma memória pode ser um frasco sem exterior" (PÊCHEUX, 1995, p. 50). Isso significa dizer que as marcas do que os italianos trouxeram como bagagem linguística à língua portuguesa no período de densa imigração deixou cicatrizes nos discursos de seus 
descendentes. Recorremos à Grammatica della lingua italiana Per Stranieri: Libro 1 - Di Base (2015) e constatamos que o plural dos substantivos em italiano ocorre pela troca dos morfemas finais dos substantivos para "i" ou para "-e", como por exemplo telefono/telefoni, persona/persone, ristorante/ristoranti. A língua italiana não tem em sua estrutura o morfema "-s" para a marcação de plurais em seus substantivos. Com relação aos verbos, nesta mesma gramática, podemos verificar que as conjugações de todos os verbos regulares em italiano não apresentam o uso do "-s" na 1a pessoa do plural para todos os tempos e modos verbais. Segundo Coracini (2013), todo o ato de enunciação transforma esse sujeito e acaba transformando a língua. Os sujeitos dos enunciados têm em sua memória linguístico-discursiva os traços tanto do italiano quanto do português, misturando as regras de ambas as línguas.

Esses sujeitos também deixam "vazar" em seus dizeres palavras que não pertencem ao léxico da sua língua materna, mas sim ao da língua outra que o constitui. 0 contrário também ocorre: quando o sujeito imigrante, ao apropriar-se da língua outra, enuncia palavras da língua italiana. Observemos os recortes discursivos a seguir. Os três primeiros foram extraídos das entrevistas feitas com os descendentes de italianos; os quatro últimos são provenientes das entrevistas feitas com os italianos:

RD1: Porque ele tinha os peccato dele lá fora (...)

RD2: Ma como tinha a nonna, o nonno (...)

RD3: (...) que em italiano se dice em Itália (...)

RD4: (...) que aquela época se falava fa... é... fez o atto di chiamata... que... que chamaram né.

RD5: (...) eu poco a poco fui aprendendo.

RD6: Ma io ia na missa lá na Rafael.

RD7: (...) devido a influência de um cliente meu carabinieri (...) 
Observando os recortes discursivos, notamos que os dizeres dos italianos e dos descendentes possuem estruturas similares, cicatrizes das línguas acontecendo uma na outra. Caso não citássemos quem enunciou cada um dos RDs, seria difícil apontar qual deles fora dito por um italiano e qual por um descendente. Isso ocorre durante diversos trechos das entrevistas e de maneira inconsciente. Baseando-nos nas acepções de Coracini (2013) e nos achados expostos, acreditamos que a submissão à língua da colônia de um povo colonizado ou de imigrantes a quem são impostas línguas estrangeiras é um processo que deixa cicatrizes, marcando suas identidades. Em tal processo, mesmo sem ter consciência, o imigrante ou colonizado acaba impondo sua cultura, costumes e línguas aos colonizadores ou anfitriões. O sujeito imigrante encontra-se ora exiliado em sua língua materna e ora exilado em línguas estrangeiras.

Esse exílio acontece com relação às línguas, aos costumes e com o próprio sujeito. Este se (des)constrói na alteridade e, portanto, por estar entre-línguas, vive entre a repulsa e a atração do que é do outro e do que é seu. "Podemos ver enlaces e desenlaces do sujeito na, das e pelas línguas, o que indica ruptura, exílio, mas também hospitalidade" (ECKERT-HOFF, 2016, p. 227).

As línguas acontecendo simultaneamente remete-nos às reflexões sobre o que seria língua estrangeira para esses sujeitos e o que seria Língua Materna. Seria a Língua Materna má ou terna? A fim de estudarmos os efeitos dessas línguas na constituição identitária dos sujeitos da pesquisa, passaremos para a segunda parte das análises.

\section{Língua materna}


Uma das perguntas elaboradas para a entrevista desta pesquisa foi direcionada à Língua Materna (LM) dos entrevistados. Ao serem questionados a respeito de qual seria sua LM, tanto os italianos quanto os descendentes demonstraram hesitação em seus dizeres, marcas que podemos verificar acontecendo na língua e das quais nos utilizaremos nas análises.

As reflexões de Amati-Mehler (2005) sobre relatos de histórias de vida de escritores acerca dessa constituição identitária do sujeito imigrante vão ao encontro de nossas acepções sobre línguas maternas e estrangeiras. Um desses casos é o do escritor Amitav Ghosh. Nascido na Índia, ele é conhecido mundialmente por suas obras escritas em inglês. O autor afirma não conseguir escrever em qualquer das outras cinco línguas que conhece, mas sente sua vida dividida em fatias de acordo com o seu pensamento e a língua que emerge junto dele em sua cabeça: ele diz pensar sobre comida em bengalês, em transportes em hindu e assuntos escolares em inglês. Dependendo do assunto, a memória traz à tona uma das línguas. Trazemos, ainda, as acepções de Amati-Mehler (2005) sobre a frase de Thomas Edward Lawrence: "aquele que tem duas línguas perde a sua alma" (AMATI-MEHLER, 2005, p. 31). Lawrence teve parte importante no serviço secreto de inteligência britânica durante a Primeira Guerra Mundial e participação na Revolta Árabe. Ainda quando era arqueólogo, cultivou grande apreço pela cultura árabe, aprendendo essa língua. Auxiliou os árabes na revolta já mencionada, tendo grande influência entre esse povo. A citação de Lawrence remete-nos a um sujeito que se encontra na confusão instaurada pela língua inglesa e a árabe, já que ele afirma que um sujeito que tem duas línguas perde a alma, o sujeito constituído por duas línguas perdese. Essa frase traz à tona a ilusão que o sujeito possui do monolinguismo, de ter sua origem proveniente de uma língua una. Esse sentimento de ilusão de que a língua que 
constitui o sujeito não sofre interferências, de que ao falar duas línguas não se consegue falar nem uma e nem outra são recorrentes nos recortes discursivos a serem apresentados.

Como separar, portanto, língua de origem e língua estrangeira? Segundo Coracini (2013, p. 48), “não há, pois, língua de partida, como não há origem, para sempre perdida, para sempre adiada. Há apenas línguas de chegada ou por chegar; há apenas a língua do outro, uma frase prometida, um sujeito à deriva". Não há separação possível entre as línguas que constituem os sujeitos.

A partir dessas observações, passemos às análises dos recortes discursivos. RD1 e RD2 são dizeres de italianos, enquanto que RD3 e RD4 foram extraídos das falas de descendentes de italianos. Essa separação dos recortes discursivos é somente informativa, já que ser constituído no entre-línguas causa efeitos semelhantes tanto nos italianos quanto nos descendentes, como veremos a seguir. No primeiro recorte discursivo, temos:

RD1: É italiano... italiano...italiano é a primeira língua a mais língua mia a nossa como io falo...

Ao responder a pergunta sobre qual seria sua língua materna, o entrevistado enuncia ser o italiano, o que repete por três vezes; entretanto, seguidamente, as palavras acabam o traindo e diz "a mais língua mia". Ao utilizar o advérbio de intensidade "mais", o sujeito acaba fazendo uma comparação implícita entre a língua italiana e a outra língua que constitui esse sujeito, no caso, a língua portuguesa. Lemos, implicitamente: "mais língua mia que a Língua Portuguesa". Traços do italiano "mia" e "io" misturam-se à estrutura que já se encontra boa parte em língua portuguesa. Podemos inferir que a 
marca do estar entre-línguas se faz presente, levando-nos a depreender que o refúgio do imigrante está tanto na sua língua de origem quanto na língua que o acolheu. Embora o sujeito de RD1 acredite ser sua língua materna a italiana, o "conflito ${ }^{i v " ~ e n t r e ~ a s ~ l i ́ n g u a s ~}$ italiana e portuguesa pode ser depreendido dos fios linguístico-discursivos por meio do "mais", do "mia" do "io", levando-nos a crer que existem duas línguas maternas para este sujeito imigrante; por vezes má, quando surgem os "conflitos" linguísticos, por vezes terna, quando acolhe.

No próximo RD, temos os dizeres de um entrevistado italiano considerando a língua italiana como materna:

RD2: Sim/ considero/ é lógico né/ é língua materna né/ apesar que não sei... ah... eu falo agora não sei falar nem italiano nem brasiliano nem nada/ é pela idade/ a gente... a gente se atrapalha né.

O RD2 traz, a princípio, os dizeres de um sujeito com certeza de que sua língua materna seria o italiano, já que era nascido na Itália: "sim”, "considero”, “é lógico né”, "é língua materna né". Entretanto, essa sequência que expõe uma certeza é quebrada com a incerteza trazida pelo "apesar que não sei". O sujeito encontra-se "atrapalhado" por estar entre as línguas italiana e brasiliana e acaba se questionando quanto a saber tanto uma quanto a outra. Isso acontece já que as línguas não encontram barreiras: a materna e a estrangeira atuam, concomitantemente e, o sujeito, que tem a ilusão de que uma única língua pode ser sua língua materna, perde-se. "O sujeito da linguagem fica sujeito à dispersão, à contradição, à (des)continuidade - algo que afeta diretamente a imagem de uma língua una" (CELADA; PAYER, 2016, p. 28). Há ao mesmo tempo o acolhimento por parte das duas línguas, mas também, o "conflito". 
A con-fusãov entre as línguas italiana e portuguesa também aparece no discurso do descendente de italianos. Os recortes discursivos a seguir foram retirados das entrevistas de descendentes de segunda ou terceira geração, aqueles que foram criados ouvindo o italiano falado pelos pais, tios, avós, em suas casas:

RD3: Ai falava as duas, né/ porque o pai e a mãe era brasileiro/ ma como tinha a nonna o nonno/ tudo/ era tudo italiano que falava/ Então a gente pequena escutava entendia e falava também quando pedia alguma coisa/ "mamma, me dà um toco de pan"/ que era pão que a gente pedia/ então essas coisa né/ a gente falava as duas né.

Em RD3 o sujeito aponta como LM as duas línguas faladas no lar: a língua do pai e da mãe que eram brasileiros e a língua do nonno e da nonna que eram italianos. Podemos inferir, portanto, que as línguas que constituem esse sujeito são as línguas da família, do refúgio, do aconchego. Notamos em "mamma me dà um toco de pan" que o sujeito acredita ter enunciado um "italiano puro", mas este apresenta marcas do português, tanto que seguidamente traz a tradução desse pedido. A tradução "que era pão que a gente pedia" é a alteridade no dizer que mostra "a reformulação se fazendo e cujo fio, heterogêneo, passa de uma língua a outra" (AUTHIER-REVUZ, 1998, p. 115). A autora ensina-nos que nesse tipo de ocorrência há uma "reformulação explícita", a qual é a marca do jogo enunciativo entre eu, o Outro e os outros ${ }^{\mathrm{vi}}$. O sujeito descendente de imigrantes é atravessado por língua e cultura de seus ancestrais, que inconscientemente e a todo o momento emergem por meio das palavras em seu enunciado. As línguas portuguesa e italiana constituem este sujeito descendente de imigrantes e, 
semelhantemente ao que já vimos com os RDs dos imigrantes, as línguas apresentam-se em forma de abrigo, mas ao mesmo tempo "conflito", as línguas más e ternas.

O último recorte discursivo traz o abrigo e o "conflito" do estar entre línguas por meio de um sujeito que hesita, gagueja ao responder a pergunta sobre a língua materna:

RD4: Olha eu é... foi a portugue... a portugue... a língua... o...o português.../ mas a gente... a minha mãe só conversava com a gente em italiano/ e a gente entendia tudo/ e eu não falava/ eu falava pouca coisa em italiano/ eu falava porque eu entendia tudo que minha mãe falava/ mas depois a gente acaba esquecendo porque não pratica (...)

O sujeito traz nesse RD a incerteza de qual língua seria sua língua materna. Podemos inferir essa oscilação por meio das hesitações materializadas pelas reticências e pelo fato de começar a mencionar a língua portuguesa por duas vezes, sem terminar a palavra portuguesa, em seguida afirmar que é o português. Mesmo após enunciar ser o português a língua materna, ainda podemos constatar as hesitações e, em seguida, a conjunção "mas", que traz a ideia de uma contradição na fala do sujeito: a língua materna é a portuguesa, mas falava-se em italiano, língua da mãe, dos avós, da família. Língua do abrigo e do "conflito", já que por ser brasileiro, o sujeito acredita ser sua língua materna a portuguesa, mas em seus dizeres, podemos depreender que não existe uma única língua materna, ou uma única que constitua esse sujeito.

Por meio dos recortes discursivos desses quatro sujeitos, pudemos depreender que a constituição de cada um deles passa, necessariamente, por pelos menos duas línguas, as quais se fundem. As breves análises desses RDs vão ao encontro de Pêcheux (1995), que apresenta como deslocamento a ideia de que o sujeito não é a origem daquilo que diz, que as palavras por ele proferidas são palavras de discursos outros, os 
quais sustentam o seu dizer. Ele tem a impressão de ser, mas não é o centro, a origem. 0 discurso dos sujeitos do bairro da Mooca é sustentado pelos dizeres outros, de seus ancestrais, os quais viveram uma Itália (re)inventada no bairro e, por conta da força da memória discursiva, ainda vemos tão fortemente as marcas dessa herança através do "mooquês" e de outras manifestações culturais entre seus moradores.

\section{Considerações finais}

Em meio à miscelânea cultural em que a cidade de São Paulo está inserida, um grupo de residentes de um bairro ítalo-brasileiro passou a ser foco deste trabalho. Tratase da Mooca, lugar onde ainda permanecem fortes raízes italianas da época da imigração do início do século XX, período este de forte desenvolvimento industrial nesse bairro operário de outrora.

Os italianos que lá se firmaram trouxeram consigo sua língua e costumes, os quais foram difundidos e passados às gerações subsequentes. Ocorreu que, tanto para o italiano, quanto para o descendente, ambos os sujeitos constituídos entre-línguas, a memória dos dizeres de seus ancestrais e daqueles que ajudaram a construir a identidade do bairro passaram a prevalecer, surgindo dessa mixagem o "mooquês" e outros costumes que fazem parte do patrimônio cultural do bairro da Mooca e da cidade de São Paulo.

Os gestos de interpretação aos recortes discursivos deste artigo levam-nos a inferir que tanto o brasileiro quanto o italiano que fazem parte desse grupo de residentes podem ser considerados como ítalo-brasileiros e (re)inventaram e (re)significaram língua e costumes em seu grupo como uma forma de tentativa de preservação de suas raízes. Os 
desdobramentos de estudos como este podem ser relevantes tanto na Linguística, por meio da criação de políticas de ensino de línguas aos imigrantes (temos uma nova leva de imigrantes na capital paulista - bolivianos, sírios, haitianos) quanto para as Ciências Humanas e Sociais no que tange à remanescência de grupos de imigrantes (italianos, japoneses, lituanos) e os impactos sócio-histórico-culturais que a tentativa da preservação de suas culturas podem acarretar à cidade de São Paulo e à sua população.

\section{Referências}

AMATI-MEHLER, Jacqueline; ARGENTIERI, Simona; CANESTRI, Jorge. A babel do inconsciente: língua materna e línguas estrangeiras na dimensão psicanalítica. Tradução Cláudia Bachi. Rio de Janeiro: Imago Editora, 2005.

ASSOLINI, Filomena Elaine. A escrita e sujeitos-professores: relações, cicatrizes, ensino e identidades profissionais. In: CELADA, M. T.; PAYER, M. O. (orgs.). Subjetivação e processos de identificação. Campinas, SP: Pontes, 2016.

AUTHIER-REVUZ, Jacqueline. Heterogeneidade(s) enunciativa(s). In: ORLANDI, E. P.; GERALDI, J. W. Cadernos de Estudos Linguísticos. Campinas, SP: UNICAMP-IEL, n. 19, jul./dez., 1990, p. 25-42.

Palavras incertas: as não coincidências do dizer. Campinas, SP: Editora da Unicamp, 1998.

BOSI, Ecléa. O tempo vivo da memória: ensaios de Psicologia Social. São Paulo: Ateliê, 2003.

CANDAU, Joel. Memória e identidade. Tradução Maria Letícia Ferreira. São Paulo: Contexto, 2014.

CELADA, Maria Teresa; PAYER, Maria Onice. Sobre sujeitos, língua(s), ensino. Notas para uma agenda. In: CELADA, M. T.; PAYER, M. O. (orgs.). Subjetivação e processo de identificação. Campinas, SP: Pontes, 2016.

CORACINI, Maria José. A subjetividade na escrita do professor. Pelotas: UCPel/EDUCAT, 2003. 
A celebração do outro: arquivo, memória e identidade. 2. ed. Campinas, SP: Mercado das Letras, 2013.

ECKERT-HOFF, Beatriz Maria. (Dis)sabores da língua ma(e)terna: os conflitos de um entrelugar. In: ECKERT-HOFF, B. M.; CORACINI, M. J. (orgs.). Escrit(ur)a de si e alteridade no espaço papel-tela: alfabetização, formação de professores, línguas materna e estrangeira. Campinas, SP: Mercado das Letras, 2010.

. Língua, memória, imigração: errâncias e travessias em relatos de cartas. In: PAYER. M. O; CELADA, M. T. Subjetivação e processos de identificação: sujeitos em práticas discursivas-inflexões no ensino. Campinas, SP: Pontes, 2016.

HALL, Stuart. A identidade cultural na pós-modernidade. 10. ed. Tradução Ezequiel T. Silva e Guacira L. Louro. Rio de Janeiro: DP\&A, 2000.

LUPIA, Márcia de Oliveira. Discurso, memória e identidade na Mooca: efeitos da imigração italiana. 2017. Dissertação (Mestrado em Linguística) - Universidade Cruzeiro do Sul, São Paulo, 2017.

MALDIDIER, Denise. Inquietação do discurso: (re)ler Michel Pêcheux hoje. Tradução Eni Orlandi. Campinas, SP: Pontes, 2003.

MELMAN, Charles. Imigrantes: incidências subjetivas das mudanças de Língua e País. São Paulo: Escuta, 1992.

Memória Globo. A próxima vítima. Disponível em:

<http://memoriaglobo.globo.com/programas/entretenimento/novelas/a-proximavitima/trama-principal.htm>. Acesso em: 06 jun. 2018.

ORLANDI, Eni. A linguagem e seu funcionamento: as formas do discurso. 5. ed. Campinas, SP: Pontes, 2009.

PAYER, Maria Onice. Memória da língua: imigração e nacionalidade. 1999. Tese (Doutorado em Linguística) - Instituto de Estudos Linguísticos/Unicamp, Campinas, SP, 1999.

. Processos de identificação sujeito/língua. Ensino, Língua Nacional e Língua Materna. In: ORLANDI, E. (org.). Política linguística no Brasil. Campinas, SP: Pontes, 2007. PÊCHEUX, Michel. Semântica e discurso: uma crítica à afirmação do óbvio. Campinas, SP: Editora Unicamp, 1995.

SÃO PAULO (cidade). Regional da Mooca. Notícias: Sotaque da Mooca pode virar patrimônio histórico. Disponível em: 
<http://www.prefeitura.sp.gov.br/cidade/secretarias/regionais/mooca/noticias/?p=2255 8>. Acesso em: 06 jun. 2018.

TARTAGLIONE, Roberto; BENINCASA, Angelica. Grammatica della lingua italiana Per Stranieri: Libro 1 - Di Base. Firenze: Alma Edizione, 2015.

VIEIRA, Marcílio Melo. Para um estudo das influências fonológicas do italiano no português falado na cidade de São Paulo. 2010. Dissertação (Mestrado em Mestrado em Letras - Língua e Literatura Italiana) - Universidade de São Paulo, São Paulo, 2010.

Recebido em 28 de agosto de 2018.

Aceite em 04 de dezembro de 2018.

\footnotetext{
'Pedido encaminhado ao Conselho pelo vereador Juscelino Gadelha em 2009. Segundo o Conpresp, eles não possuem corpo técnico qualificado para fazer esse tipo de análise, já que um processo de tombamento como este deve analisar materiais que possam comprovar a importância do sotaque, como vídeos, fotos, gravações e transcrições.

ii Os recortes discursivos utilizados são provenientes das entrevistas semiestruturadas feitas em virtude da pesquisa de Dissertação de Mestrado de Lupia (2017), sob a orientação da Profa. Dra. Beatriz Eckert-Hoff. Projeto de Pesquisa aprovado pelo Comitê de Ética em 29/03/2017, parecer $n^{\circ} 1.989 .495$, CAAE $^{\circ}$ 64381717.7.0000.8084.

iii Adotaremos, para os fins desta pesquisa, o termo "entre-línguas", utilizado por Coracini em estudos no grupo de pesquisas da "Da Torre de Marfim à Torre de Babel" e por Eckert-Hoff (2010) em seus estudos sobre imigrantes alemães no Brasil.

iv Utilizamos a palavra conflito entre aspas por entendermos que o conflito tratado nas análises não possui o sentido negativo de sua denotação.

vTermo emprestado de Coracini (2013), que significa fusão entre as línguas.

${ }^{\mathrm{vi}} \mathrm{A}$ alteridade discursiva marcada pelo outro (com letra minúscula) e o Outro (com letra maiúscula) deve ser vista por meio da acepção de Assolini (2016) a partir de Lacan: no primeiro caso, a ênfase se coloca no lugar e na função do nosso semelhante da espécie humana, nossos iguais. No segundo, o Outro configura-se enquanto campo simbólico da linguagem, formado por todos os outros que, na infância, ocuparam lugares importantes, como por exemplo, mãe, pai, avó, avô, tio, tia, professores. Esse grande Outro é o lugar do inconsciente (ASSOLINI, 2016, p. 127).
} 